\title{
Assessing Managers' Attitudes Toward Health Promoting Hospitals at a Teaching Hospital in Tehran, Iran
}

\author{
Mohsen Saberi Isfeedvajani ${ }^{1}$, Esmat Davoudi-Monfared ${ }^{2 *}$, Akbar Nikpajouh ${ }^{3}$, Yaser Nasiri Moghadam ${ }^{4}$ \\ ${ }^{1}$ Medicine, Quran and Hadith Research Center \& Department of Community Medicine, Faculty of Medicine, Baqiyatallah \\ University of Medical Sciences, Tehran, Iran \\ ${ }^{2}$ Health Management Research Center \& Department of Community Medicine, Faculty of Medicine, Baqiyatallah University \\ of Medical Sciences, Tehran, Iran \\ ${ }^{3}$ Rajaie Cardiovascular Medical and Research Center, Iran University of Medical Sciences, Tehran, Iran \\ ${ }^{4}$ Faculty of Medicine, Baqiyatallah University of Medical Sciences, Tehran, Iran
}

*Corresponding Author: Esmat Davoudi-Monfared, M.D., Assistant Professor, Health Management Research Center \& Department of Community Medicine, Faculty of Medicine, Baqiyatallah University of Medical Sciences, Tehran, Iran. Tel: +98021-81263850. Email: davoudimonfared@gmail.com

Received September 28, 2020; Accepted November 17, 2020; Online Published December 1, 2020

\begin{abstract}
Background: Hospitals are the most important and largest providers of health services in the health system.

Objectives: This study aimed to examine hospital managers' attitudes toward health promotion policies at a teaching hospital in Tehran, Iran.

Methods: This research was a descriptive-analytical study. The study population consisted of 75 senior and middle managers of a teaching hospital in Tehran, Iran in 2018. Sampling was conducted through a census. The study instrument was a researcher-made questionnaire assessing managers' attitudes toward health promotion. The questionnaire was validated. Data were collected and then analyzed using SPSS 20 software.

Results: Total score of health promotion policies was estimated to be $84.5 \pm 10.6$ out of 100 . The highest scores of the components associated with health promotion policies were $94.9 \pm 9.34$ and $93.8 \pm 10.36$ of 100 belonging to "Awareness of hospital staff of health promotion policies" and "Enjoyment of a written health promotion policy" items, respectively; while the lowest score was $75.4 \pm 20.68$ out of 100 belonging to "Informing patients, their companions, and staff about factors associated with the disease whose health is supported by the hospital". The highest score of components associated with health promotion activities was $94.1 \pm 9.74$ out of 100 belonging to "Increasing patients' trust by providing health promotion services" item and the lowest was $72.2 \pm 19.4$ out of 100 belonging to "Assessment of patient's needs for health promotion" item.

Conclusion: Hospital managers' attitudes score was high toward health promotion policies and activities, but there are still problems with health promotion activities, the most important of which is a therapeutic-centered perspective.

Keywords: Health Promotion, Hospitals, Attitude, Managers
\end{abstract}

\section{Background}

Health promotion is defined in WHO's Ottawa Charter for Health Promotion as a broader concept and as a process empowering people to increase control and improve their health. ${ }^{1}$

Ottawa Charter defines five preferred areas of health promotion activities: building healthy community policy, creating supportive environments for health, strengthening community action for health, developing personal skills, and reorienting health services. ${ }^{2}$ Ottawa Charter promoted the idea that "health is created and lived by people within the settings of their everyday life; where they learn, work, play, and love" by considering health as a positive concept. This environmental approach to health promotion which is associated with the settings of everyday life has led to initiatives such as health-promoting cities, health-promoting schools, and health promoting hospitals ( $\mathrm{HPH})$, etc. so that the health of people can be promoted in places where they spend most of their time. ${ }^{3}$ This environmental approach is adopted based on social experience and organizational development. ${ }^{4}$

The idea of creating HPH was first presented at the WHO Global Health Promotion Conference in 1986 by the World Health Organization and has been steadily expanding and progressing throughout the world to this day. ${ }^{1}$ Purpose of $\mathrm{HPH}$ is to transform a hospital from a mere diagnostic

Copyright (C) 2020 The Author(s). This is an open-access article distributed under the terms of the Creative Commons Attribution License (http:// creativecommons.org/licenses/by/4.0), which permits unrestricted use, distribution, and reproduction in any medium, provided the original work is properly cited. 
and therapeutic site to a disease prevention and health promotion place for patients, staff, clients, and all members of society. ${ }^{5,6}$ Although many people regard hospitals as a health promotion setting, there are still differences in attitudes toward the actual impact of these hospitals on public health in practice, and the idea of health promotion is slowly developing in hospitals. ${ }^{7}$ Policymaking, planning, implementing, and monitoring of health promotion activities are the requirements of moving toward a healthpromoting hospital, ${ }^{8,9}$ and hospital managers' attitudes toward health promotion policies and programs are particularly important in achieving the mentioned goals.

The main reason for the slow implementation of health promotion programs in hospitals was limited to the understanding of the concept of health promotion hospital at management leve ${ }^{10}$ and lack of commitment to coordination and performing planning activity. ${ }^{11}$

\section{Objectives}

This study was conducted to design a valid questionnaire and determine the managers' attitudes of a teaching hospital in Tehran toward the implementation of healthpromoting policies in the hospital.

\section{Methods}

This research was a cross-sectional study. The study population included all managers working in organizational positions associated with health promotion in a 700-bed teaching hospital in Tehran, Iran in 2018. The sample of this study consisted of 75 senior and middle managers working in organizational positions such as administrative, financial, and medical management whose field of work is directly or indirectly associated with health promotion processes, and sampling was conducted through a census. The inclusion criteria were the following: managers who have been employed over five years in hospital and in senior and middle management positions for more than two years. The exclusion criteria were dissatisfaction with participation in the study.

In the first step, a research instrument was designed by overviewing the available documentation (articles and books) and expert opinion (who were skilled in concepts, planning, and implementing of $\mathrm{HPH}$ programs). The questionnaire included 24 items in two domains of health promotion policies and activities based on five-point Likert scale and its validity and reliability were evaluated in this study. The validity of instrument was assessed using face and content validity approaches. The face validity of the questionnaire was assessed through qualitative and quantitative methods. Face validity was qualitatively evaluated by a five-member panel consisting of technical experts and health promotion professors, three of the panel members are social medicine experts (two of them are $\mathrm{HPH}$ experts and one of them is an HPH researcher) and two of the panel members hold $\mathrm{PhDs}$ in epidemiology and health education and are experts in designing a questionnaire to measure difficulty level, degree of irrelevancy, ambiguity in phrases, or incomprehensibility in meanings and their corrective comments were applied to the questionnaire. The impact score of each item was calculated in order to evaluate the face validity quantitatively. First, the 5-point Likert scale was considered for each item of the questionnaire: strongly agree (scored 5), agree (scored 4), neither agree nor disagree (scored 3), disagree (scored 2 ), and strongly disagree (scored 1). The total score was considered 100 and therefore attitude scores were interpreted as follows: below 20 completely negative, 20 to 39 negative, 40 to 59 neither negative nor positive, 60 to 79 positive, and 80 to 100 completely positive. Then, the designed instrument was distributed among 11 technical experts and professors of health promotion who were asked to examine items based on the mentioned criterion. Then the importance of each instrument item was calculated using the impact score formula:

\section{Impact Score $=$ Frequency $(\%) \times$ Importance}

And, the results were compared with the standard score. The items whose scores were higher than the standard score were included in the questionnaire. Next, the content validity of the instrument was analyzed using content validity ratio (CVR) and content validity index (CVI) (Table 1). CVR was used to ensure that the most important and correct content (item essentiality) is selected. And CVI was used to ensure that the instrument items are best designed to measure the content. Eleven respondent experts also participated in this phase. Experts were asked to group items as "essential", "essential but not useful", or "not essential" in order to calculate CVR. Their responses were calculated based on CVR formula and the results were compared with Lawshe's Table. Numbers higher than 0.59 were approved.

CVI survey was performed based on the Waltz and Basel content validity index..$^{12}$ The questionnaire was distributed among the experts who were asked to rank 24 items based on the four-part Likert scale as compatible with three criteria of relevancy, simplicity, and clarity. (For example, unrelated items, partially related items, related items, and fully related items were scored 1, 2, 3, and 4, respectively). CVI score was calculated by dividing the sum of the compatible scores for each item (i.e. items scored 3 and 4 which are the highest scores) by the total number of experts. Items higher than 0.79 were approved according to CVI score.

After evaluating the validity of questionnaire, Cronbach's alpha method was used to assess its reliability. The reliability obtained was high with a Cronbach's alpha of 0.84 .

Questionnaires were distributed among the population of this study after standardization. The method of data collection was self-completed and questionnaires were collected within 48 hours after distribution considering confidentiality principles by the trained researcher.

Collected data was analyzed using SPSS 20 software. The scoring basis of questionnaires on the Likert scale 
Table 1. Content Validity Index of Questionnaires Through CVR and CVI

\begin{tabular}{|c|c|c|}
\hline Item & CVR & CVI \\
\hline The hospital should have a written health promotion policy. & 1 & 0.97 \\
\hline In general, health promotion is always the central core of medicine, especially in the hospital. & 0.8 & 0.75 \\
\hline Hospital recognizes its health promotion responsibilities. & 0.64 & 0.85 \\
\hline The hospital should ensure that its staff is committed to conducting health promotion activities. & 0.8 & 0.94 \\
\hline Health promotion is considered as a form of service. & 0.2 & 0.82 \\
\hline Hospital staff should be aware of health promotion policies. & 1 & 1 \\
\hline Hospital allocates the resources needed to implement health promotion programs. & 1 & 1 \\
\hline Hospital evaluates patients' health promotion needs in the hospital. & 1 & 0.97 \\
\hline Patients' needs for health promotion are assessed for the first time they enter the hospital. & 0.64 & 0.91 \\
\hline The hospital supports actions done to inform patients, their companions, and staff about factors associated with disease and their health. & 1 & 0.94 \\
\hline $\begin{array}{l}\text { Patients should receive clear, understandable, and appropriate information about their real condition, treatment, care, and factors affecting } \\
\text { their health in the hospital. }\end{array}$ & 0.64 & 0.94 \\
\hline The hospital ensures a safe and healthy work environment. & 0.45 & 0.85 \\
\hline Hospital guarantees training and development of its staff health promotion skills. & 0.82 & 0.97 \\
\hline The organization has a planned approach to continuously work with other levels of health services and other institutions and departments. & 0.45 & 0.91 \\
\hline The quality of health promotion programs is monitored and evaluated in the hospital. & 1 & 0.94 \\
\hline Health promotion of hospital staff influences patient satisfaction. & 1 & 0.97 \\
\hline Health promotion services have a positive impact on the physician-patient relationship. & 0.64 & 0.91 \\
\hline Health promotion services increase patients' trust. & 0.64 & 0.94 \\
\hline Health promotion services increase patients' quality of life although they are sick. & 0,82 & 0.94 \\
\hline Health promotion services improve the interaction of the patient with healthcare staff. & 0.64 & 0.94 \\
\hline Health promotion services empower patients to deal with disease and cooperate with healthcare staff. & 0.45 & 0.91 \\
\hline Health promotion activities will be performed in the hospital during outpatient care and after the patient's discharge. & 0.82 & 0.94 \\
\hline The development and implementation of health promotion services reduce the amount of unnecessary hospitalization. & 0.82 & 0.97 \\
\hline What do you regard as the main obstacles to provide health promotion services in the hospital? & 1 & 0.97 \\
\hline
\end{tabular}

was changed to 100 . Frequency distribution, mean, and standard deviation were used successively to perform descriptive tests for qualitative and quantitative variables. Moreover, Mann-Whitney, $t$ test, and Kruskal-Wallis tests were used for inferential statistics. The significance level was set at $5 \%$ in this study.

\section{Results}

4.1. Evaluating the Validity and Reliability of the Instrument of This Study

The findings of Table 2 show that since the scores of all items of the questionnaire were higher than the criterion score (i.e. 1.5), experts approved the quantitative face validity of all items.

The results of CVR show that "Health promotion is considered as a form of service", "Hospital ensures a safe and healthy work environment", "Organization has a planned approach to continuously work with other levels of health services and other institutions and departments", and "Health promotion services empower patient to deal with disease and cooperate with healthcare staff" that are items of the questionnaire with a score smaller than 0.59 based on Lawshe's Table, and thus experts did not recognize them as essential items to be included in the final version of the questionnaire.

Moreover, the results of CVI indicate that all items of the questionnaire except for "In general, health promotion is always the central core of medicine, especially in hospital" obtained a score higher than 0.79 and were considered as appropriate items by experts. Furthermore, the score of the mentioned item was 0.75 , and it thus needs to be revised. The reliability of the questionnaire based on Cronbach's alpha was $0.77,0.83$, and 0.88 for policies, activities, and questionnaires, respectively.

\subsection{Study Findings}

Attitudes of 75 managers (58 male managers (77.3\%) and 17 female managers $(22.7 \%)$ ) were evaluated in this study (Table 3).

The total score of managers' attitude toward health promotion policies was estimated to be $84.5 \pm 10.6$ out of 100 and the total score of their attitude toward health promotion activities of the hospital was estimated to be $85.3 \pm 8.65$ out of 100 . The highest scores of components associated with health promotion policies were $94.9 \pm 9.34$ and $93.8 \pm 10.36$ out of 100 belonging to "Awareness of hospital staff of health promotion policies" and "Enjoyment of a written health promotion policy" items, respectively. The lowest scores of components associated with health promotion policies were $75.4 \pm 20.68$ and $77 \pm 19.36$ out of 100 belonging to "Hospital supports actions done to inform patients, their companions, and staff about factors associated with disease and their health" and "Resources needed for implementation of health promotion programs 
Table 2. Results of Calculating Quantitative Face Validity (Impact Score) of Items of the Designed Instrument

\begin{tabular}{|c|c|c|c|}
\hline Item & Frequency & Importance & Impact Score \\
\hline The hospital should have a written health promotion policy. & 9.5 & 1 & 9.5 \\
\hline In general, health promotion is always the central core of medicine, especially in the hospital. & 13.4 & 0.8 & 10.7 \\
\hline Hospital recognizes its health promotion responsibilities. & 9.4 & 0.91 & 8.5 \\
\hline The hospital should ensure that its staff is committed to conducting health promotion activities. & 7.9 & 1 & 7.9 \\
\hline Health promotion is considered as a form of service. & 9.25 & 0.82 & 7.57 \\
\hline Hospital staff should be aware of health promotion policies. & 11.3 & 1 & 11.3 \\
\hline Hospital allocates the resources needed to implement health promotion programs. & 6.4 & 1 & 6.4 \\
\hline Hospital evaluates patients' health promotion needs in the hospital. & 9.5 & 1 & 9.5 \\
\hline Patients' needs for health promotion are assessed for the first time they enter the hospital. & 9.25 & 0.91 & 8.4 \\
\hline $\begin{array}{l}\text { The hospital supports actions done to inform patients, their companions, and staff about factors associated with } \\
\text { disease and their health. }\end{array}$ & 11.3 & 1 & 11.3 \\
\hline $\begin{array}{l}\text { Patients should receive clear, understandable, and appropriate information about their real condition, treatment, } \\
\text { care, and factors affecting their health in the hospital. }\end{array}$ & 11.71 & 0.73 & 7.79 \\
\hline The hospital ensures a safe and healthy work environment. & 10.9 & 0.82 & 8.9 \\
\hline Hospital guarantees training and development of its staff health promotion skills. & 9.5 & 1 & 9.5 \\
\hline $\begin{array}{l}\text { The organization has a planned approach to continuously work with other levels of health services and other } \\
\text { institutions and departments. }\end{array}$ & 9 & 0.73 & 6.55 \\
\hline The quality of health promotion programs is monitored and evaluated in the hospital. & 9.5 & 1 & 9.5 \\
\hline Health promotion of hospital staff influences patient satisfaction. & 6.4 & 1 & 6.4 \\
\hline Health promotion services have a positive impact on the physician-patient relationship. & 10.86 & 0.82 & 8.9 \\
\hline Health promotion services increase patients' trust. & 9.25 & 0.82 & 7.8 \\
\hline Health promotion services increase patients' quality of life although they are sick. & 9.4 & 0.91 & 8.5 \\
\hline Health promotion services improve the interaction of the patient with healthcare staff. & 7.8 & 0.91 & 7.1 \\
\hline Health promotion services empower patients to deal with disease and cooperate with healthcare staff. & 10.14 & 0.73 & 7.4 \\
\hline $\begin{array}{l}\text { Health promotion activities will be performed in the hospital during outpatient care and after the patient's } \\
\text { discharge. }\end{array}$ & 7.8 & 0.91 & 7.1 \\
\hline $\begin{array}{l}\text { The development and implementation of health promotion services reduce the amount of unnecessary } \\
\text { hospitalization. }\end{array}$ & 13.3 & 1 & 13.3 \\
\hline What do you regard as the main obstacles to providing health promotion services in the hospital? & 6.4 & 1 & 6.4 \\
\hline
\end{tabular}

are allocated by hospital" items, respectively. The highest scores of components associated with health promotion activities were $94.1 \pm 9.74$ and $93.1 \pm 10.65$ out of 100 belonging to "Increasing patients' trust by providing health promotion services" and "Impact of health promotion of hospital staff on patient satisfaction" items, respectively. The lowest scores of components associated with health

Table 3. Descriptive Statistics of Managers Adopting Attitudes Toward Health Promoting Hospitals

\begin{tabular}{llll}
\hline & & Frequency & Percentage \\
\hline \multirow{2}{*}{ Educational } & Bachelor's degree \& below & 31 & 41.3 \\
level & Master's degree \& higher & 44 & 58.7 \\
& Total & 75 & 100 \\
& $\leq 10$ years & 22 & 31.4 \\
Years of job & $10-20$ years & 27 & 38.6 \\
& $>20$ years & 21 & 30 \\
& Total & 70 & 100 \\
Years of & $\geq 5$ years & 32 & 50 \\
management & $6-15$ years & 22 & 34.4 \\
& $>15$ years & 10 & 15.6 \\
& Total & 64 & 100 \\
Organizational & $16 \geq$ & 27 & 48.2 \\
Degree & $17 \leq$ & 29 & 51.8 \\
& Total & 56 & 100 \\
\hline
\end{tabular}

promotion activities were $65.6 \pm 21.2$ and $72.2 \pm 19.4$ out of 100 belonging to "Assessment of patients' needs for health promotion for the first time they enter the hospital" and "Performing health promotion activities in the hospital during outpatient care and after patient's discharge" items, respectively (Table 4).

Managers of this study recognized therapeutic-centered perspective, lack of resources, lack of health promotion professionals, lack of human resources as main obstacles to providing health promotion services. The frequency of these obstacles equaled $36,28,19$, and $17 \%$ for therapeuticcentered perspective, lack of resources, lack of health promotion professionals, and lack of human resources, respectively. The mean scores of health promotion policies of the hospital were significantly different for male and female managers $(P=0.02)$. Scores that male managers gave to health promotion policies of the hospital were significantly higher than the scores that female managers gave to health promotion policies of the hospital.

Mean scores of hospital health promotion activities were not significantly different between male and female managers $(P=0.904)$.

There was no statistically significant difference between mean scores given to health promotion policies and 
Table 4. The Mean and Standard Deviation of Components Associated With Hospital Policies and Activities Toward Health-Promoting Hospital

\begin{tabular}{|c|c|c|c|}
\hline & Item & Mean & Standard Deviation \\
\hline \multirow{10}{*}{$\begin{array}{l}\text { The domain of } \\
\text { health promotion } \\
\text { policies }\end{array}$} & Enjoyment of a written health promotion policy & 93.8 & 10.36 \\
\hline & Health promotion as a medical central core at the hospital level & 87.2 & 15.64 \\
\hline & Responsibility for health promotion is recognized by hospital & 86.7 & 17.18 \\
\hline & Commitment of hospital staff to health promotion activities is ensured by hospital & 88.5 & 14.02 \\
\hline & Awareness of hospital staff of health promotion policies & 94.9 & 9.34 \\
\hline & Resources needed for the implementation of health promotion programs are allocated by the hospital & 77 & 19,36 \\
\hline & Evaluation of patients' needs for health promotion & 79.2 & 15.92 \\
\hline & $\begin{array}{l}\text { The hospital supports actions done to inform patients, their companions, and staff about factors associated } \\
\text { with disease and their health. }\end{array}$ & 75.4 & 20.68 \\
\hline & Training and development of staff health promotion skills are guaranteed by the hospital & 78.1 & 19.5 \\
\hline & The total score of policies & 84.5 & 10.6 \\
\hline \multirow{11}{*}{$\begin{array}{l}\text { The domain of } \\
\text { health promotion } \\
\text { activities }\end{array}$} & Assessment of patients' needs for health promotion for the first time they enter the hospital & 65.6 & 21.2 \\
\hline & $\begin{array}{l}\text { Receiving clear, understandable, and appropriate information about the real condition of treatment, care, } \\
\text { and factors affecting health in hospital }\end{array}$ & 90.4 & 14.84 \\
\hline & Monitoring and evaluating the quality of health promotion programs in hospital & 73.2 & 21.12 \\
\hline & Impact of health promotion of hospital staff on patient satisfaction & 93.5 & 10.45 \\
\hline & Positive impact of health promotion services on the physician-patient relationship & 89.6 & 15.2 \\
\hline & Increasing patients' trust by providing health promotion services & 94.1 & 9.74 \\
\hline & Improving patients' quality of life despite disease by providing health promotion services & 93.1 & 10.65 \\
\hline & Improving the interaction of the patient with healthcare staff by providing health promotion services & 91.5 & 11.47 \\
\hline & $\begin{array}{l}\text { Performing health promotion activities in the hospital during outpatient care and after the patient's } \\
\text { discharge }\end{array}$ & 72.2 & 19.4 \\
\hline & $\begin{array}{l}\text { Reducing the amount of unnecessary hospitalization through the development and implementation of } \\
\text { health promotion services }\end{array}$ & 90.1 & 12.02 \\
\hline & A total score of activities & 85.3 & 8.65 \\
\hline
\end{tabular}

activities of the hospital by managers with different education levels, work and managerial experience, and organizational status.

\section{Discussion}

This study showed that managers of a hospital had a very high score of attitude toward establishing health promotion policies (scored 84.5 out of 100) and implementation of health promotion activities in the hospital (scored 85.3 out of 100).

Since hospitals have wide access to healthcare professionals, they have a high capacity to formulate and implement $\mathrm{HPH}$ services. Other studies have pointed to similar results consistent with the results of the present study. Khowaja et al conducted a study on hospital staff and participants of their study had a positive attitude toward $\mathrm{HPH}$ and regarded it beneficial for patients, society, and hospital staff. ${ }^{13}$

"Awareness of hospital staff of health promotion policies"; the item of this study has the highest score in policy domain. Other studies have reported varying levels of awareness of health promotion. Afshari et al researched hospital specialists and concluded that most participants had limited awareness of health promotion policies and activities. ${ }^{14}$ Richard et al performed an investigation on nurses and claimed that health promotion is often defined as larger-scale health education. A significant number of participants were unable to define health promotion clearly. ${ }^{15}$ Khowaja et al stated in their study that only those who had a health-related education defined health promotion more comprehensively and had understood the preventive role of hospitals well. ${ }^{16}$

Hospital managers of this study believed that hospitals have written health promotion policies. It seems that other studies reported that overall health promotion policies have been preferred to practical activities in this domain. Whitehead et al carried out a review and found that although health promotion has been addressed in theoretical texts and overall policies, it is not frequently observed in executive activities and published studies are mostly on the theoretical dimension of health promotion. In fact, there are fewer activities performed about its application in health centers. ${ }^{17}$ Results of this study show that managers have considered an increase in trust and satisfaction of patients as the result of providing health promotion services in hospitals as the best advantage of $\mathrm{HPH}$ executive activities. Casey et al in their study claimed that providing health promotion services in hospitals was an important factor in improving the quality of life of patients. ${ }^{18}$ Moreover, the lowest executive scores of this study belonged to "Assessment of patients' health promotion needs" and "Performing health promotion activities in the hospital during outpatient care and after patient's discharge". Studies show when chronic patients are informed about disease status and factors affecting it, they can control the condition better and they are more 


\section{Research Highlights}

\section{What Is Already Known?}

Health promoting hospitals have been founded to transform the hospital from a therapeutic site to a health promotion place. Although health promotion has been addressed in theoretical texts and overall policies of hospitals, it is not frequently observed in executive activities and the idea of health promotion is slowly developing in hospitals.

\section{What This Study Adds?}

Hospital managers have a positive attitude toward health promotion policies and activities but there are still obstacles to the implementation of health promotion activities, the most important of which is a therapeuticcentered perspective.

satisfied with received services. ${ }^{19.20}$ Lee et al conducted a review study and stated that hospitals need regular organizational support to fulfill their role in promoting the health of society. However, many of the identified obstacles are not solely due to insufficient organizational support because poor coordination and integration of health promotion services into hospital services can be an important factor in failing to implement action plans for patients. ${ }^{21}$ Studies have shown that insufficient knowledge and understanding of health care professionals about the concept of HPH is an obstacle to effective implementation of related programs in hospitals. ${ }^{22}$

\section{Conclusion}

The hospital managers' attitudes score was high toward health promotion policies and activities, but there are still problems and obstacles to health promotion activities, the most important of which is a therapeutic-centered perspective. Establishing infrastructure, coordinating, and integrating health promotion services into hospital services can help the implementation of $\mathrm{HPH}$ action plans in hospitals. It is suggested to emphasize on positive perspectives and attitudes of the majority of managers in future studies in order to address obstacles and problems of implementing $\mathrm{HPH}$ and applying it in the patient's visiting process.

\section{Authors' Contributions}

Study design: MSI, AN; Data collection: YN; Data analysis: YN; Manuscript writing: ED; Critical revisions for important intellectual content: ED.

\section{Conflict of Interest Disclosures}

There was no conflict of interest in this research.

\section{Ethical Approval}

Participants participated in the study with informed consent and their anonymity and confidentiality were respected.

\section{Acknowledgments}

Thanks to financial support, guidance, and advice from the "Clinical Research Development Unit of Baqiyatallah Hospital" and full appreciation to Nooredin Dopeykar for his sincere cooperation.

\section{References}

1. World Health Organization (WHO). Ottawa Charter for Health Promotion. https://www.who.int/teams/health-promotion/ enhanced-wellbeing/first-global-conference.

2. Whitelaw S, Baxendale A, Bryce C, MacHardy L, Young I, Witney E. 'Settings' based health promotion: a review. Health Promot Int. 2001;16(4):339-353. doi:10.1093/heapro/16.4.339.

3. Petersen PE, Kwan S. The 7th WHO Global Conference on Health Promotion-towards integration of oral health (Nairobi, Kenya 2009). Community Dental Health. 2010;27(Suppl 1):129-136. doi:10.1922/CDH_2643Petersen08.

4. Thompson SR, Watson MC, Tilford S. The Ottawa Charter 30 years on: still an important standard for health promotion. Int J Health Promot Educ. 2018;56(2):73-84. doi:10.1080/146352 40.2017.1415765.

5. Groene O, World Health Organization. Implementing Health Promotion in Hospitals: Manual and Self-Assessment Forms. Copenhagen: WHO Regional Office for Europe; 2006.

6. Waring J, Allen D, Braithwaite J, Sandall J. Healthcare quality and safety: a review of policy, practice and research. Sociol Health Illn. 2016;38(2):198-215. doi:10.1111/14679566.12391.

7. Johnson A, Baum F. Health promoting hospitals: a typology of different organizational approaches to health promotion. Health Promot Int. 2001;16(3):281-287. doi:10.1093/ heapro/16.3.281.

8. Whitelaw S, Baxendale A, Bryce C, MacHardy L, Young I, Witney E. 'Settings' based health promotion: a review. Health Promot Int. 2001;16(4):339-353. doi:10.1093/heapro/16.4.339.

9. Dooris M. Healthy settings: challenges to generating evidence of effectiveness. Health Promot Int. 2006;21(1):55-65. doi:10.1093/heapro/dai030.

10. Guo XH, Tian XY, Pan YS, et al. Managerial attitudes on the development of health promoting hospitals in Beijing. Health Promot Int. 2007;22(3):182-190. doi:10.1093/heapro/dam010.

11. Al Aufa B. Management process of health promoting hospital in a private hospital, Lamongan, East Java. In: 3rd International Conference on Vocational Higher Education (ICVHE 2018). Atlantis Press; 2020. p. 284-289. doi:10.2991/ assehr.k.200331.154.

12. Waltz CF, Bausell RB. Nursing Research: Design, Statistics, and Computer Analysis. Philadelphia: F.A. Davis Company; 1981.

13. Khowaja AR, Mistry R, Agha A, Karmaliani R. Potential benefits and perceived need for health promoting hospitals in Pakistan: a healthcare stakeholder's perspective. J Pak Med Assoc. 2010;60(4):274-279.

14. Afshari A, Ghahnaviyeh LA, Khezeli M, Daniali SS. Health promotion perception among health-care providers working in educational hospitals of Isfahan, Iran: a qualitative study. J Educ Health Promot. 2019;8:144. doi:10.4103/jehp.jehp_336_18.

15. Richard L, Gendron S, Beaudet N, Boisvert N, Sauvé MS, Garceau-Brodeur MH. Health promotion and disease prevention among nurses working in local public health organizations in Montréal, Québec. Public Health Nurs. 2010;27(5):450-458. doi:10.1111/j.1525-1446.2010.00878.x.

16. Khowaja AR, Karmaliani R, Mistry R, Agha A. Transition towards health promoting hospitals: adapting a global framework to Pakistan. East Mediterr Health J. 2011;17(10):738-743. doi:10.26719/2011.17.10.738.

17. Whitehead D. Health promotion and health education: 
advancing the concepts. J Adv Nurs. 2004;47(3):311-320. doi:10.1111/j.1365-2648.2004.03095.x.

18. Casey D. Nurses' perceptions, understanding and experiences of health promotion. J Clin Nurs. 2007;16(6):1039-1049. doi:10.1111/j.1365-2702.2007.01640.x.

19. Yeatman HR, Nove T. Reorienting health services with capacity building: a case study of the Core Skills in Health Promotion Project. Health Promot Int. 2002;17(4):341-350. doi:10.1093/ heapro/17.4.341.

20. Meyer C, Muhlfeld A, Drexhage C, et al. Clinical research for patient empowerment--a qualitative approach on the improvement of heart health promotion in chronic illness. Med Sci Monit. 2008;14(7):CR358-365.

21. Walthew P, Scott H. Conceptions of health promotion held by pre-registration student nurses in four schools of nursing in New Zealand. Nurse Educ Today. 2012;32(3):229-234. doi:10.1016/j.nedt.2011.04.013.

22. Lee CB, Chen MS, Powell MJ, Chu CM. Organisational change to health promoting hospitals: a review of the literature. Springer Sci Rev. 2013;1(1):13-23. doi:10.1007/s40362-0130006-7 